\title{
Comparative Study Between Dexmedetomidine And Magnesium sulfate Added to Bupivacaine In Spinal Anesthesia For Postoperative Analgesia In Patients Undergoing Perianal Surgeries
}

\section{Mohamed Hussien M., Ahmed El-Saied A., Khaled Mohamed H., Mohamed Abdelrehem M.}

\begin{abstract}
Introduction

Spinal anesthesia is the most commonly used technique for lower abdominal surgeries as it is very economical and easy to administer. A number of adjutants, such as Opioids , Clonidine, and Midazolam have been studied to prolong the effect of spinal anesthesia (ELIA, et al 2008).

Dexmedetomidine a new highly selective a2- agonist is under evaluation as a neuraxial adjuvant as it provides stable hemodynamic conditions, good quality of intraoperative and postoperative analgesia with minimal side effects (Kanazi and AlGhanem 2009).

Magnesium sulfate $(\mathrm{Mg})$ is an antagonist of $\mathrm{N}$-methyl D Aspartate receptor (NMDA) improves postoperative analgesia after intrathecal administration as an effective adjuvant to bupivacaine (Soave and Arcangeli 2009).
\end{abstract}

Aim of the work

To compare the postoperative analgesic effects and any side effects ofdexmedetomidine and magnesium sulfate $(\mathrm{Mg})$ when added to bupivacaine in spinal anesthesia in patientsundergoing perianal surgeries.

\section{Patients and methods}

Ninty ASA physical status I and II patients aged 18-70 years, of either sex, scheduled for perianal surgeries under spinal anesthesia in this prospective randomized, double-blinded study.

\section{Results}

All the Mg cases needed analgesia within 4 hours postoperative, while for all the Dex cases needed analgesia within5 hours postoperative. The difference between the two groups was highly significant.

Key words

Spinal Anesthesia - Postoperative Analgesia - Dexmedetomidine - Magnesium sulfate - Perianal Surgeries.

\section{Introduction}

Pain is defined by the International Association for the Study of Pain (IASP) as an unpleasant sensory and emotional experience associated with actual or potential tissue damage, or described in terms of such damage,(Merskey and Bogduk, 1994).

Pain assessment can be straight forward and brief in the setting of acute pain related to trauma or surgery. It increases in complexity and the time required as the pain becomes persistent, fails to respond to conventional therapy,(Portenoy and Kanner, 1996).

Pain assessment is done by: a)Numeric rating scale: Patients indicate their pain intensity on a scale of 0to 10, with 0 indicating no pain and 10 the worst pain imaginable.

b) Verbal rating scales consist of a series of words commonly used to describe pain (e.g., no pain, mild pain, moderate pain, severe pain).

c)Visual analog scale consists of a 10$\mathrm{cm}$ line with one end labeled "no pain" 
and the other end labeled "worst pain imaginable."

d)Faces pain scale presents pictures of 6 to 8 different facial expressions depicting a range of emotions,(Jensen and McFaraland, 1993), (Bieri et al, 1990).

Dexmedetomidine is a potent and highly selective $\alpha-2$ adrenoceptor agonist with sympatholytic, sedative, amnestic, and analgesic properties which has been described as a useful and safe adjunct in many clinical applications. It is the most recently developed and commercialized agent in this pharmacological class,(Carollo and Nossaman 2008).

The hypnotic effect of dexmedetomidine is mediated by the hyperpolarization of noradrenergic neurons in the locus ceruleus of the brain stem. When the $\alpha-2$ adrenergic receptor is activated, it inhibits adenylyl cyclase. This latter enzyme catalyzes the formation of cyclic AMP (cAMP), a crucial second messenger molecule that acts in many catabolic cell processes. By reducing the amount of cAMP in the cell, dexmedetomidine favors anabolic over catabolic pathways. Simultaneously, there is an efflux of potassium through calcium-activated potassium channels and an inhibition of calcium entry into calcium channels in nerve terminals, (Khan and Ferguson 1999 ).

The incidence of postoperative bradycardia has been reported to be as high as $40 \%$ in healthy patients. These temporary effects have been managed with atropine, ephedrine, and volume infusion. Caution should be taken in those clinical situations where the sympatholytic actions of $\alpha-2$ receptor agonists prove detrimental, such as in patients with left ventricular dysfunction and when administered to patients who are volume depleted, vasoconstricted, or have severe heart block,(Haselman 2008).
MgSO4 was first used to prevent eclamptic seizures in 1906 by Horn in Germany, who injected it intrathecally' . An intramuscular regimen was used in 1926 to prevent recurrent seizures in women with eclampsia2 and the drug was given intravenously in 1933 to women with pre-eclampsia and eclampsia,(Lazard 1933).

Although it is recognised as an anticonvulsant, significant falls in blood pressure have been observed during use of the recommended therapeutic doses of $\mathrm{MgSO}$, the hypotensive action was transient. This transient hypotensive effect has been consistently noted with a bolus infusion and high dose continuous infusion by some authors,(Scardo and, Hogg 1995).

The first sign of magnesium toxicity is usually the loss of tendon (patella) reflexes. This occurs with plasma levels > $5 \mathrm{mmoVL}$, with respiratory depression occurring at levels $>6 \mathrm{mmol} / \mathrm{L}$, (Winkler and Smith 1942) .

Other early signs and symptoms of toxicity include nausea, feeling of warmth, flushing, somnolence, double vision, slurred speech and weakness (usually at 3.8 to $5 \mathrm{~mm} 01 \mathrm{~L}$ ), Muscular paralysis and respiratory arrest will develop at plasma levels of 6.3 to 7.1 $\mathrm{mmol} / \mathrm{L}$, Cardiac arrest will develop at plasma levels of 12.5 to $14.6 \mathrm{~mm} 1 / \mathrm{L}$, ( Sibai 1990 ).

\section{Patients and methods}

We included 90 ASA physical status I and II patients aged 18-70 years, of either sex, scheduled for perianal surgeries under spinal anesthesia in this prospective randomized, double-blinded study.

\section{Exclusion criteria:}

Patients with a history of

1- Uncontrolled hypertension.

2- heart block/dysrhythmia.

3- Therapy with adrenergic receptor antagonist, calcium channel blocker, 
opium addiction, sedative drugs consumption.

4- Contraindication for spinal anesthesia .

The patients were preloaded with Lactated Ringer's solution $15 \mathrm{ml} / \mathrm{kg}$, lumber puncture was performed at the L4-L5 level in the sitting position through a midline or lateral approach using $25 \mathrm{G}$ spinal needles under complete aseptic precautions.

Using computer-generated random numbers, patients were allocated into two groups:

(Group $\mathrm{Mg}$ ) to receive $2.5 \mathrm{ml}$ volume of $0.5 \%$ hyperbaric bupivacaine and $50 \mathrm{mg}$ magnesium sulphate $(0.5 \mathrm{ml}$ magnesium sulphate, ampule $1000 \mathrm{mg}$ in $10 \mathrm{ml}-$ Epico) plus $0.5 \mathrm{ml}$ of normal saline.

(Group Dex) to receive $2.5 \mathrm{ml}$ volume of $0.5 \%$ hyperbaric bupivacaine and 10ug dexmedetomidine in $1 \mathrm{ml}$ of normal saline (dexmedetomidine $100 \mathrm{ug} / \mathrm{ml}$ was diluted in preservativefree normal saline).

Intrathecal injection was given over approximately 10-15s. Patients were positioned in sitting position 5$10 \mathrm{~m}$ after completion of the injection as trial for achievement of saddle block and oxygen $2 \mathrm{~L} / \mathrm{min}$ was given through a face mask if the pulse oximeter reading decreased below $90 \%$.

We will measure pulse and blood pressure (systolic and diastolic) after intrathecal injection at $1 \mathrm{~min}, 5 \mathrm{~min}, 10 \mathrm{~min}, 15 \mathrm{~min}, 20 \mathrm{~min}, 25 \mathrm{~min}$ and 30min intraoperative and $2 \mathrm{hrs}, 4 \mathrm{hrs}, 6 \mathrm{hrs}$ and $12 \mathrm{hrs}$ postoperative

Sensory block was assessed bilaterally by using sensory response to pin prick with a short hypodermic needle in the midclavicular line to be sure we reach the target sensory level and we measure sensory regression to $\mathrm{S} 1$ postoperative .

Motor block assessed by Modified Bromage scale,(Bromage et al 2007):

$\mathbf{0}=$ Able to raise legs above table.

$\mathbf{1 = I n a b i l i t y ~ t o ~ r a i s e ~ e x t e n d e d ~ l e g s . ~}$

$\mathbf{2}=$ Inability to flex knees.

$\mathbf{3}=$ Inability to flex ankles.

Intraoperative complications should be noted like Respiratory Depression ,Itching , Shivering , Nausea , Vomiting , Desaturation , Hypotension, Bradycardia.

Duration of complete analgesia was defined as the time from spinal injection to the first report of pain when VAS >0 and duration of effective analgesia was defined as the time from spinal injection to the first rescue analgesics requirement when VAS reached 4 or more it is the end of spinal analgesia and need to additional analgesia $(0=$ No pain, $10=$ Most severe pain),( Scardo and, Hogg 1995).

The rescue analgesics consisted of intravenous infusion of ketolac $30 \mathrm{mg} / 2 \mathrm{ml}$ (Alamrya pharm) (maximum daily dose 60mg) when VAS reached 4or more. Patients were discharged at Bromage 0 to home. 


\section{Results}

Table 1 (the onset of sensory and motor block of study group)

\begin{tabular}{|c|c|c|c|c|}
\hline & $\begin{array}{c}\text { Dex group } \\
\text { Mean } \pm \text { SD }\end{array}$ & $\begin{array}{l}\text { Mg group } \\
\text { Mean } \pm \text { SD }\end{array}$ & T Test & P Value \\
\hline Duration of Surgery (Minutes) & $0.11 \pm 4.825$ & $6.22 \pm 2.173$ & 4.930 & $<0.001$ \\
\hline Pnset of Sensory Block (Minutes) & $1.33 \pm 0.505$ & $1.31 \pm 0.468$ & 2.166 & 0.063 \\
\hline Onset of Motor Block (Minutes) & $3.04 \pm 0.520$ & $2.58 \pm 0.499$ & 4.340 & $<0.001$ \\
\hline
\end{tabular}

This table shows that the surgical duration was nearly 20 minutes in Dex group and 16 minutes in $\mathrm{Mg}$ group with highly significant difference between the two groups.

The onset of motor block was much faster in the $\mathrm{Mg}$ group (Mean $2.58 \pm$ 0.499)compared to the Dex group (Mean $3.04 \pm 0.520$ ), with a highly significant difference motor block and no significant difference in sensory block between the two groups.

Table 2 (post operative pain assessment)

\begin{tabular}{|r|c|c|c|}
\hline & Dex group & Mg group & P value \\
\hline $\begin{array}{c}\text { Time when VAS exceeded 0 } \\
\text { (complete analgesia)(Min) }\end{array}$ & 240 & 200 & $<\mathbf{0 . 0 0 1}$ \\
\hline $\begin{array}{c}\text { Time when VAS exceeded4 } \\
\text { (effective analgesia) (Min) }\end{array}$ & 300 & 240 & $<\mathbf{0 . 0 0 1}$ \\
\hline Sensory regression to S1(Min) & 200 & 180 & 0.466 \\
\hline Bromage 0(Min) & 220 & 200 & 0.354 \\
\hline
\end{tabular}

This table shows that all of the $\mathrm{Mg}$ cases needed analgesia within 4 hours postoperative, while for all of the Dex cases needed analgesia within5 hours postoperative. The difference between the two groups was highly significant. 
Table 3 (complications may appear in the study groups)

\begin{tabular}{|c|c|c|c|c|}
\hline & Dex group & Mg group & Chi square & $\mathrm{P}$ value \\
\hline Respiratory Depression & 0 & 0 & & \\
\hline Itching & 0 & 0 & & \\
\hline Shivering & 8 & 11 & 0.6 & 0.438 \\
\hline Nausea & 0 & 0 & & \\
\hline Vomiting & 13 & 7 & 2.314 & 0.128 \\
\hline Desaturation & 0 & 0 & & \\
\hline Hypotension & 17 & 22 & 1.131 & 0.288 \\
\hline Bradycardia & 34 & 6 & 35.280 & $<\mathbf{0 . 0 0 1}$ \\
\hline
\end{tabular}

This table shows shivering, vomiting, hypotension \&bradycardia complications are recorded in both groups. Shivering occurred in 8 cases in the Dex group, compared to 11 cases in $\mathrm{Mg}$ group, with nosignificant difference.

Vomiting occurred in 13 cases in the Dex group, compared to 7 cases in $\mathrm{Mg}$ group, with no significant difference. Hypotension occurred in 17 cases in the Dex group, compared to 22 cases in Mg group, with nosignificant difference, while bradycardia occurred in 34 cases in the Dex group, compared to 6 cases in $\mathrm{Mg}$ group, with highly significant difference.

\section{Analgesic Administration}

Total dose of rescue analgesic on both groups when vas exceed $>4$ was 2 Amp Ketolac(60mg) on both groups. Quality of intraoperative analgesia was excellent and postoperative analgesiawas good.

\section{Discussion}

Gupta et al and ALghanem et al found intrathecal Dexmedetomidine with bupivacaine is associated with prolonged motor and sensory block with hemodynamic stability and in our study we found that Dexmedetomidine actually prolong sensory and motor block and the blood pressure was stable but there is noticed bradycardia in $70 \%$ of cases and these bradycardia may be dose dependent as we used $10 \mu \mathrm{gDexmedetomidine} \mathrm{but} \mathrm{Gupta} \mathrm{et} \mathrm{al}$ and ALghanem et al used 5 $\mu \mathrm{g}$, (Gupta et al 2011)( Al ghanem et al 2009).

Arcioni observed also that intrathecal $\mathrm{Mg}$ sulfate prolonged sensory and motor block with hemodynamic stability and this is agree with our study as $\mathrm{Mg}$ sulfate when added to bupivacaine prolong sensory and motor block and the pulse and blood pressure were stable, (Arcioni and Palmisani 2007).

On the other hand in Magnesium group the onset of motor block was faster than Dex group (Mean onset of motorblock 2.58minute ) but against our study, Ozalevli et al observed a delay in onset of motor block when addingintrathecalMg sulfate (Mean onset of motor block $2.8 \mathrm{~min}$ ) but this is may be dose dependent also as Ozalevli et al used $0.1 \mathrm{ml} \mathrm{Mg}$ sulfate and we used $0.5 \mathrm{ml} \mathrm{Mg}$ sulfate in our study, (Ozalevli et al 2005).

Malleeswaran et al found that the onset of sensory block was statistically prolonged in $\mathrm{Mg}$ sulfate group compared to Dexmedetomidine group but this is against our study as we found the onset of sensory block was nearly the same in both groups( Mean onset of sensor block in $\mathrm{Mg}$ group $1.31 \mathrm{~min}$ and in Dex group $1.33 \mathrm{~min}$ ) ,(Malleeswaranet al 2010). 
Haselman found that the incidence of bradycardia with Dexmedetomidinehas been reported to be as high as $40 \%$ in healthy patients, but in our study bradycardia was reported in $70 \%$ of cases ,(Haselman2008) .Khezri et al and Singh et al found that the addition of dexmedetomidine to bupivacaine increases the duration of analgesia significantly post operative more than $\mathrm{Mg}$ sulfate, and these result agree with our study as we found that in Dex group VAS $>4$ at 300 min maximally postoperative and in $\mathrm{Mg}$ group VAS $>4$ at 240min maximally,(Khezri et al 2014) (Singh et al 2013).

\section{Conclusion}

Addition of dexmedetomidine prolonged the sensory and motor block significantly when used with hyperbaric bupivacaine intrathecally, without increasing the incidence of significant adverse effects.

Intrathecal Magnesium also prolongs the duration of sensory and motor block, but lesser than Dexmedetomidine.

\section{References}

1- Elia N., Culibras X., Mazaa C., Schiffer E. and Tramer M.R.: Clonidine as an adjuvant to intrathecal local anesthetics for surgery: Systematic review of randomized trials. Reg. Anesth. Pain Med.2008, 33: $159-67$

2- KanaziG.E., AouadM.T., JabbourKhoury S.I., AL Jazzar M.D.,ALAMEDDINE M.M., ALYAMAN R., et al.: Effect of low-dose dexmedetomidine or clonidine on the characteristics of bupivacaine spinal block. Acta. AnesthesiolScand,2006, 50: 222-7

3- Soave PM, Conti G, Costa R, Arcangeli A.: Magnesium anaesthesia. Curr Drug Targets;(2009), 10:734-43.

4- Merskey H \&Bogduk N Classification of Chronic Pain, IASP
Task Force on Taxonomy. Seattle, IASP Press(1994).

5- Portenoy RK, Kanner RM: Definition and assessment of pain. In: Portenoy RK, Kanner RM, eds. Pain Management: Theory and Practice. Philadelphia, PA: FA Davis; (1996):7

6- Jensen MP, McFarlandCA: Increasing the reliability and validity of pain intensity measurement in chronic pain patients. Pain. (1993);55:195-203

7- Bieri D, Reeve RA, Champion GD, et al: The Faces Pain Scale for the self-assessment of the severity of pain experienced by children: development, initial validation, and preliminary investigation for ratio scale properties. Pain.(1990); 41:139-150.

8- Carollo DS, Nossaman BD, Ramadhyani U Dexmedetomidine: a review ofclinical applications. CurrOpinAnaesthesiol 2008;21:457461.

9- Khan ZP, Ferguson CN, Jones RM - Alpha-2 and imidazoline receptor agonists:their pharmacology and therapeutic role. Anaesthesia 1999;54:146-165.

10- Haselman MA - Dexmedetomidine: a useful adjunct to consider in some high-risk situation. AANA J 2008;76:335-339

11- Lazard EM. An analysis of 575 cases of eclamptic and pre eclamptictoxaemias treated by IV injections of magnesium sulphate. Am J ObstetGynecol1933; 26: 647656.

12- Scardo JA, Hogg BB, Newman RB. Favourable hemodynamic effects of magnesium sulphate in pre eclampsia. Am J ObstetGynecol 1995 173: 1249-1253.

13- Winkler AW, Smith PK, Hoff HE. Intravenous magnesium sulphate in the treatment of nephritic 
convulsions in adults. J Clin Invest 1942 21: 207-216.

14- Sibai BM. Eclampsia VI .Maternalperinatal outcome in 254 consecutive cases. Am JObstetGynecoll990; 163: 10491055.

15- Bromage P.R.: An evaluation of bupivacaine in epidural analgesia for obstetrics. Can. Anesth. Soc. J.1969, 16: 46-56,.

16- AL-Ghanem S.M., Massad I.M., AL-Mustafa M.M., AL-Zaben K.R.,QUDAISAT I.Y., QATAWNEH A.M. and ABU-ALI H.M.: Effect of addingdexmedetomidine versus fentanyl to intrathecal bupivacaine on spinal blockcharacteristics in gynecological procedures: A double blind controlled study. Am. J.Appl. Sci.2009, 6: 882- 7,.

17- Gupta R., Reetu V., Bogra J., Kohli M., Raman R. and Kushwaha J.K.: Acomparative study of intrathecaldexmedetomidine and fentanyl as adjuvant to bupivacaine, J. AnesthesiolClin. Pharmacol. JulSep., 27 (3), 2011: 339-343.

18- Arcioni R, Palmisani S, Tigano S, et al. Combined intrathecal andepidural magnesi-um sulfate supplementation of spinal anesthesia to reduce post-operative analgesic requirements: a prospective, randomized, double- blind, controlled trial in patients undergoing major orthopedic surgery. ActaAnaesthesiol Scand. 2007;51:482-9.

19- Ozalevli M, Cetin TO, Unlugenc $\mathrm{H}$, Guler T, Isik G. The effect of adding intrathecal magnesium sulphate to bupivacaine-fentanyl spinal anaesthesia. ActaAnaesthesiol Scand. 2005;49:1514-9.

20- Malleeswaran S, Panda N, Mathew $\mathrm{P}$, Bagga R. A randomised study of magnesium sulphate as an adjuvant to intrathecal bupivacaine in patients with mild preeclamp-sia undergoing caesarean section. Int J ObstetAnesth. 2010;19:161-6.

21- Khezri MB, Rezaei M, DelkhoshReihany M, Haji SeidJavadi E. Comparison of post-operative analgesic effect of intrathecal clonidine and fentanyl added to bupivacaine in patients undergoing cesarean section: a prospective randomized doubleblind study. Pain Res Treat. 2014;2014:513628.

22- Singh R, Gupta D, Jain A. The effect of addition of intrathecal clonidine to hyperbaric bupivacaine on postoperative pain after lower segment caesarean section: A random-ized control trial. Saudi J Anaesth. 2013;7:283-290. 